\title{
NEUTRON IRRADIATION INFLUENCE ON MOBILITY AND COMPENSATION OF DARK CONDUCTIVITY IN SILICON
}

\author{
J.V. Vaitkus, A. Mekys, V. Rumbauskas, and J. Storasta \\ Institute of Applied Research and Department of Semiconductor Physics, Vilnius University, Sauletekio 3, LT-10222 Vilnius, \\ Lithuania \\ E-mail: juozas.vaitkus@ff.vu.lt
}

Received 19 December 2015; revised 27 April 2016; accepted 21 June 2016

\begin{abstract}
The electrical properties of the neutron irradiated Si were analysed by means of the Hall effect and magnetoresistance temperature dependence. It was demonstrated that the electron mobility decreased with increasing the neutron fluence in a wide fluence range, and the microinhomogeneities in samples caused differences between the mobility values from the measured Hall and magnetoresistance effects. Exploiting the magnetoresistance mobility temperature dependence, the free carrier concentration dependence on temperature was analysed. It was found that the neutron irradiation introduced deep levels in the upper part of the bandgap, but their contribution decreased with increasing the neutron fluence - that is explained by more effective generation of acceptor type levels in the middle or lower part of the bandgap. The activation energy of the free carrier concentration did not follow the homogeneous semiconductor model, so the dark conductivity origin, that is related to the modified cluster model and cluster environment, was proposed.
\end{abstract}

Keywords: radiation defects, electron mobility, Hall and magnetoresistance mobilities, clusters, silicon

PACS: 72.10.Fk, 72.20.My, 72.80.Cw, 72.20.Fr, 71.55.Cn

\section{Introduction}

The radiation hardness is very important for the devices that must function under the exposure of intense ionizing radiation [1]. The degradation of such devices is caused by the changes of detector properties due to the defects introduced by the radiation. The change of properties with irradiation fluence has been thoroughly investigated, but the properties of the detector bulk material have not been completely understood. Different impurity content, especially oxygen and carbon, in the initial Si single crystals can cause different reactions between the radiation induced defects and the impurities, leading to a dependence of radiation hardness on the initial Si properties and the device technology, e. g. thermal treatment [2], but the nature of these changes is not clear enough. Among the open questions in the investigation of radiation defects is the analysis of deep levels and details of the conductivity mechanism in the irradiated material. It is well known that hadron irradiation introduces defects that decrease the conductivity (an effect of the donor removal [ [3]), but this compensation was not analysed in the bulk of the sample. Simulation of neutron induced radiation defects illustrates a quite complicated inhomogeneous distribution of the defects [- Therefore it is important to investigate the role of those defects in the carrier trans- port. The defect size and type, the space charge regions around the defect and the concentration are important contributors for the free carrier behaviour, their drift path and trapping.

Nowadays there are many modelling attempts of ionizing radiation detector properties. The independence of free carrier mobility on the irradiation defects is commonly used. This assumption is based on the free carrier mobility investigation in the neutron irradiated silicon at a rather low fluence (up to $2 \cdot 10^{14} \mathrm{~cm}^{-2}$ ) and by an indirect way [5]. The Hall effect measurements were used to analyse the free carrier concentration in irradiated silicon samples [ [6]. Also, a weak dependence of drift mobility on the neutron irradiation fluence was found, but the measurements were performed only up to the $5 \cdot 10^{13} \mathrm{~cm}^{-2}$ neutron fluence 阿.

Carrier transport phenomena also depend on the material homogeneity, therefore the peculiarities of these phenomena can give information related to the material homogeneity [8-9]. It is especially important to analyse the limit up to which a random distribution of defects does not influence the free carrier transport character, and when the overlap of the space charge regions causes the appearance of percolation phenomena [10]. The investigation of samples irradiated to higher fluencies demonstrated the difference in the temperature dependence of the Hall and 
magnetoresistance mobility [1], and this work presents a more detailed analysis of the properties of irradiated high resistivity silicon, which is commonly used for the high energy physics applications (e. g. for the Large Hadron Collider and for its upgrade).

\section{Samples and methods}

The high resistivity (HR) $(\sim 1 \mathrm{k} \Omega \mathrm{cm}) \mathrm{MCZ}$ and FZ silicon samples were mainly investigated. The HR samples were fabricated during the CERN RD50 WODEAN project. The irradiation of samples to the $1 \mathrm{MeV}$ neutron equivalentfluence from $10^{12} \mathrm{n} / \mathrm{cm}^{2}$ to $3 \cdot 10^{16} \mathrm{n} / \mathrm{cm}^{2}$ was performed at the TRIGA research reactor of the Jozef Stefan Institute in Ljubljana. The samples were irradiated at room temperature, but the sample temperature increased by $20-30{ }^{\circ} \mathrm{C}$ during the irradiation to the fluence $1-3 \cdot 10^{16} \mathrm{n} / \mathrm{cm}^{2}$.

The HR silicon samples for the Hall effect investigation were fabricated by cutting the wafer into $7 \times 2 \times 0.28 \mathrm{~mm}$ bars, and colloidal carbon planar contacts were produced. For a test of some general tendencies the samples of low resistivity silicon were also manufactured. The same size planar Hall type samples were fabricated, and the $\mathrm{n}^{*}$-n contacts were formed by the phosphorus diffusion. The contact properties were controlled by measuring the current dependence on the bias voltage and showing it to be linear in all samples. The control measurements were carried out at room temperature (RT). The temperature dependence of Hall and magnetoresistance effects was investigated in a temperature range of $100-300 \mathrm{~K}$.

The experimental setup is given in Fig. 1. The Hall voltage measurements were performed with a B7-30 (1 T $\Omega$ input resistance) or Keithley 6514 (200 T $\Omega$ input resistance or higher) multimeter; the current through the sample was measured with a Keithley 6430 multimeter, which was simultaneously used as the voltage source. All measurements were performed in a cryostat in $10^{-2}$ to $10^{-3}$ Torr vacuum. The magnet was calibrated by a Lake Shore 455DSP gaussmeter, and Linear Hall Effect sensors P/N CYS166A were used for the current control of the magnetic field.

The Hall mobility $\mu_{\mathrm{H}}$ and the magnetoresistance mobility $\mu_{\mathrm{M}}$ in homogeneous crystals are related to the data obtained from the Hall effect and the magnetoresistance effect measurements by the following relations [12]:

$$
\mu_{\mathrm{H}}=\frac{E_{\mathrm{H}}}{B E_{X}},
$$

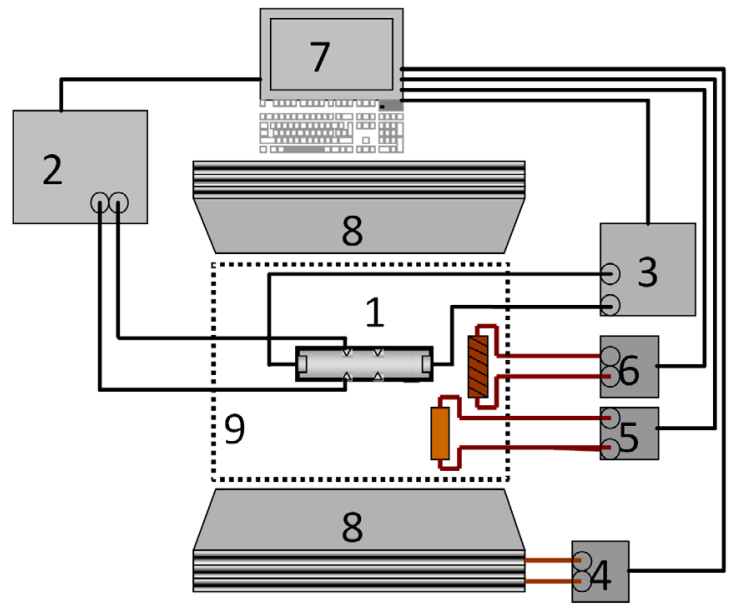

Fig. 1. Hall effect measurement scheme: sample (1); electrometer Keithley 6514 (2); source meter Keithley 6430 (3); magnet source (4, brown online); thermo resistance meter Agilent 34401 A (5, brown); heater source TTi QL564P (6, brown); computer (7); magnet (8); cryostat (9).

$$
\mu_{\mathrm{M}}=\frac{1}{B} \sqrt{\frac{\rho_{B}-\rho_{0}}{\rho_{0}}}=\frac{1}{B} \sqrt{\frac{I_{0}-I_{B}}{I_{B}}} .
$$

Here $E_{\mathrm{H}}$ is the Hall field, $E_{X}$ is the bias electric field, $B$ is the applied magnetic induction, $\rho_{0}$ and $\rho_{B}$ are the resistivity, and $I_{0}$ and $I_{\mathrm{B}}$ are the electric current with the magnetic field absent and applied, respectively. The linearity of the Hall effect and quadratic dependence of the magnetoresistance with magnetic induction was observed.

The Hall mobility $\mu_{\mathrm{H}}$ in homogeneous crystals is related to the conductivity mobility by the factor $r_{\mathrm{H}}$, i. e. $\mu_{\mathrm{H}}=r_{\mathrm{H}} \mu$, where $\mu$ is the drift mobility. In an early work the value of the Hall factor for high resistivity $\mathrm{Si}$ was measured and it was found to be $r_{\mathrm{H}}=1.15$ [13]. The magnetoresistance mobility $\mu_{\mathrm{M}}$ is related to the Hall mobility by an additional factor $\zeta$ dependent on the free carrier scattering mechanism [14], i. e. $\mu_{\mathrm{M}}=r_{\mathrm{H}} \zeta \mu=r_{\mathrm{M}} \mu$. The Hall and the magnetoresistance mobilities were observed to be proportional in the samples of the same configuration and irradiated by the high energy electrons. Details of this experiment are presented in [15], and it was found that the ratio of the magnetoresistance and the Hall mobilities $\mu_{\mathrm{M}} / \mu_{\mathrm{H}}=1.15$. As the ratio of the magnetoresistance and the Hall mobility is accidentally also equal to 1.15 (with no more than $5 \%$ error) [16] in the measured temperature range, the approximation of $\mu_{\mathrm{M}}=\mu$ was used for the evaluation of the free carrier concentration dependence on temperature. 


\section{Results}

\subsection{Electron mobility dependence on the neutron irradiation fluence}

The mobility dependence on the neutron irradiation fluence in the silicon samples is given in Fig. 2. The measurements were performed in the samples just irradiated by the reactor neutrons and in the same samples annealed at $80{ }^{\circ} \mathrm{C}$ temperature for 24 hours. It is known that the neutron irradiation creates clusters and vacancies [ $\left[\right.$ ], and annealing at $80^{\circ} \mathrm{C}$ temperature causes the migration of single vacancies to create their complexes, which reduces the defect concentration [2].

It was found that the irradiation starting from the $10^{12} \mathrm{~cm}^{-2}$ neutron fluence reduced the electron mobility. A small increase of the mobility in the samples irradiated to the neutron fluence $10^{16} \mathrm{~cm}^{-2}$ range is attributed to the increase of the sample tempera-

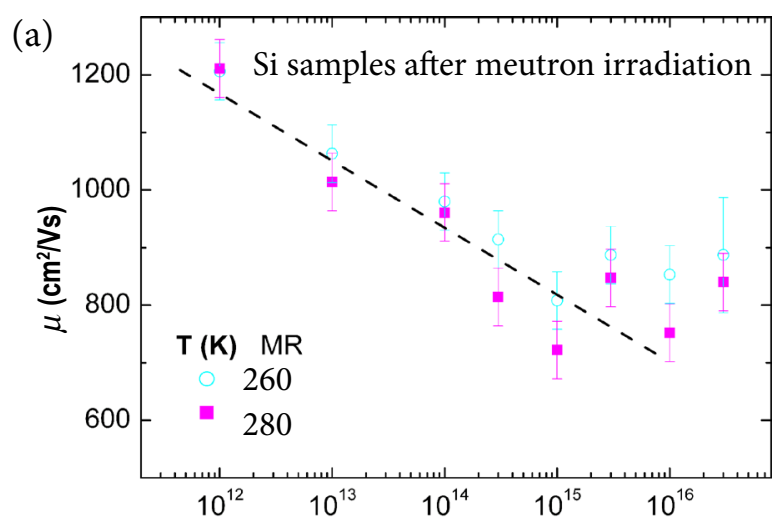

(b)

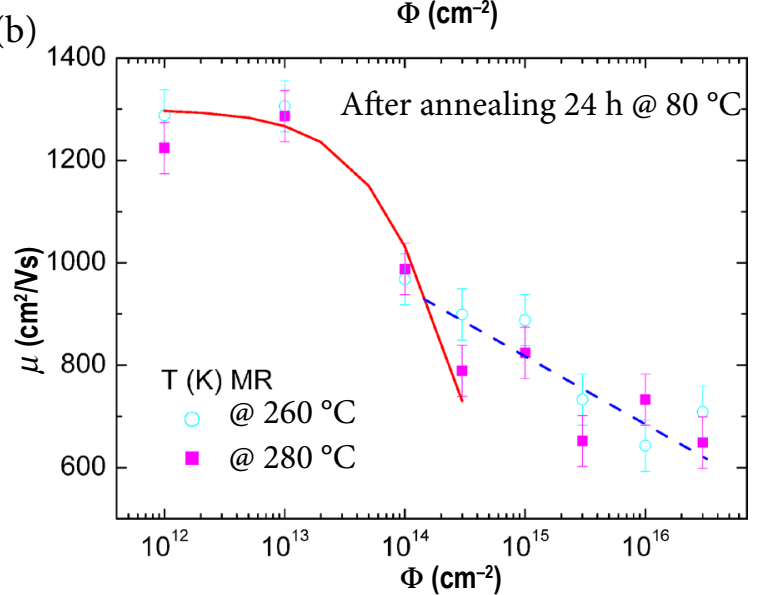

Fig. 2. Dependence of electron mobility on neutron irradiation fluence in the just-irradiated (a) and annealed for $24 \mathrm{~h}$ at $80^{\circ} \mathrm{C}$ temperature (b) samples. The full line (red online) in (b) illustrates the fitting of the experimental data to Eq. (3). The dash line in (a) and (b) (blue online) is the same approximation of the mobility dependence on the fluence and is given as a guide to the eye. The measurement temperature is given in the inset. ture during the irradiation that is mentioned previously. If the latter point is excluded from the analysis, the decrease of the mobility is seen with an increase of the fluence $\Phi$. The annealing at $80{ }^{\circ} \mathrm{C}$ temperature increases the mobility of the defects therefore it was observed that the electron mobility was restored to the values as those of non-irradiated ones in the samples irradiated to the fluence $10^{12}-10^{13} \mathrm{~cm}^{-2}$, but the decrease of the carrier mobility follows the same linear approximation in the samples irradiated to the higher fluence than $10^{14} \mathrm{~cm}^{-2}$, and it is shown in Fig. 2(a, b).

The observed restoration of the carrier mobility in the annealed sample to its value near to that in the initial sample showed that at this fluence the irradiation did not generate many scattering centres. A rather evident decrease of the mobility in the annealed samples irradiated to the fluence $10^{14} \mathrm{~cm}^{-2}$ shows that a contribution of an additional free carrier scattering mechanism becomes important. It can be related to the clusters and the point defects that were introduced by neutron irradiation and did not anneal. The observed change of the mobility in the neutron irradiated samples was more significant than it was observed in the Si samples irradiated by electrons [16] that generate the point defects, and this decrease was near to $10 \%$ at RT in the samples irradiated to $10^{16}$ electrons $/ \mathrm{cm}^{2}$.

In the case of the semiconductor with scattering of the charge carriers by phonons and ionized or neutral defects, the mobility of the carriers can be simulated by application of the Mattiessen's rule [17]. In our case the irradiation created different centres, therefore the mobility dependence on the fluence could be expressed as

$$
1 / \mu=1 / \mu_{\mathrm{phon}}+\sum_{i} \delta_{i} N_{i}(\Phi),
$$

where a sum term includes all scattering centres created by irradiation, and, if the centres reactions were neglected, the $\delta_{i}$ characterizes an effective efficiency of the scattering by a certain type of defects, and $N_{i}$ is the concentration of this type of the scattering centres. A rather abrupt decrease of mobility in the irradiated sample allows one to propose that one type of the scattering centres dominates, therefore an approximation of one type of the scattering centres can be applied. It allowed evaluating an effective scattering cross-section of these centres. For this purpose the simplified relation (3) was used:

$$
1 / \mu=1 / \mu_{\mathrm{phon}}+\delta \mathrm{N}(\Phi) .
$$

As the scattering by the impurities is usually characterized byscattering the cross-section and concentration of the defects, in our case it is possible only to receive 
the effective values. By taking into account the results from [ [ 4 , where it was found that the $10^{14} \mathrm{~cm}^{-2}$ neutron fluence introduces approximately $10^{14} \mathrm{~cm}^{-3} \mathrm{de}$ fects, it is possible to extract the effective cross-section of the scattering centres using a modified ConwellWeisskopf formula [18] where the scattering radius was taken as the radius of a Coulomb well at the depth of $k T$, and taking into account the decision 19] that this model better corresponds to the cases with a random distribution of the scattering centres. The mobility is approximated by the relation

$$
\mu=\frac{e}{m_{n}} \frac{c_{c}}{v_{n} S_{n} N_{I}},
$$

where $c_{c}$ is the correction factor, $m_{n}$ is the electron effective mass, $e$ is the electron charge, $v_{n}$ is the electron velocity, $S_{n}$ and $N_{I}$ are the scattering cross-section and the concentration of the ionized defects, respectively. The correction factor $c_{c}$ is of the order of 0.58 in our case $\left(T=200-300^{\circ} \mathrm{C}\right)$, and the concentration of the free carriers is $10^{14}-10^{15} \mathrm{~cm}^{-3}$ 18. The evaluation according to Eq. (5) and the standard values for Si gives the scattering cross section $10^{-14} \mathrm{~cm}^{-2}$ that is in a range of scattering by the charged defects. The dependence (5) was applied for the case of the annealed samples, and the results are presented in Fig. 2(b). A fit to the experimental data was achieved only in the region of fluence $10^{12}-10^{14}$ neutrons $/ \mathrm{cm}^{2}$, and it gave the mobility value independent of the fluence $\mu_{\text {phon }}=1300 \mathrm{~cm}^{2} /(\mathrm{sV})$ and the value of $\delta \mathrm{N}=2.5 \cdot 10^{-18} \mathrm{sV}$ in the annealed samples.

As Eq. (4) does not explain the dependence of the mobility on the fluence in the initial (not annealed) samples, and in the samples irradiated to the higher than $10^{14} \mathrm{~cm}^{-2}$ neutron fluence, it shows that the simple one type scattering centre model is not valid for these cases. The dependence of the mobility on the neutron fluence in these samples manifested a more complicated transform of the free carrier transport. It could be proposed that the electron transport changes because of the change of the scattering mechanism due to generation of many types of additional scattering centres with different charge that changes the classical transport to the percolation type current in nearly disordered media. A more detailed analysis of this dependence is complicated because there appears an increase of the defect concentration (scattering centres with different scattering cross-section) and the increase of the compensation by increasing the fluence, and it needs additional investigations.

These results could be important for the analysis of the irradiated detector properties because the assumption of the independence of the free carrier mobility on the irradiation is used (e. g. [20]).
Possible electron scattering processes can be clarified by the analysis of the mobility temperature dependence (Fig. 3). The decrease of the Hall mobility upon neutron irradiation was observed in an early paper [21] and explained by the model proposing the clusters as insulating spheres [22]. Also, a similar model including the concept of the effective media was proposed for the inhomogeneities related to the dislocations in GaAs [23], and this model was used to explain the difference of the Hall and magnetoresistance mobilities in Si [11]. As these models are sensitive to many parameters, they cannot
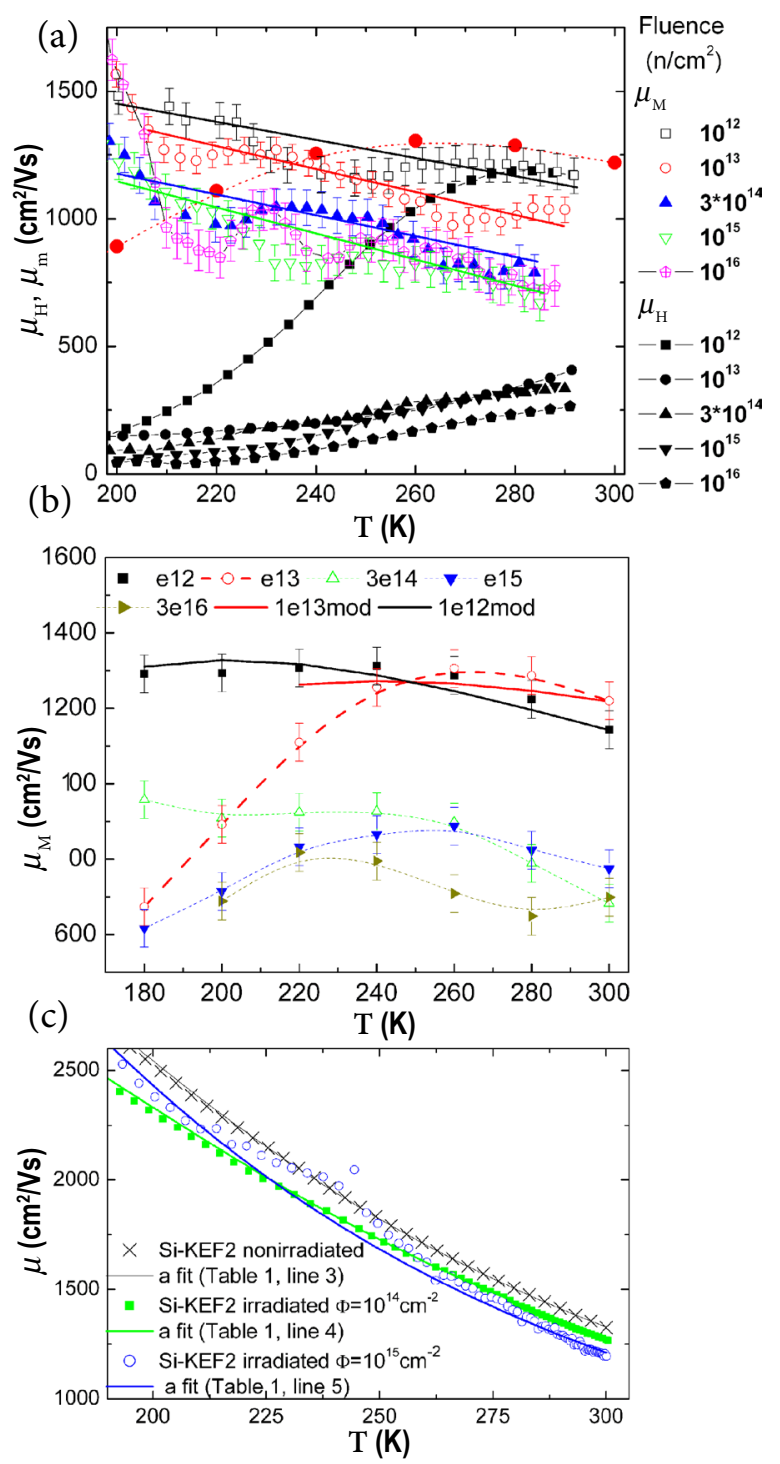

Fig. 3. Hall mobility and magnetoresistive mobility dependence on temperature in the neutron irradiated samples. The fluence and the mobility type are shown in the inset. (a) High resistivity Si samples (before annealing) (lines are linear approximations within the measurement errors); (b) irradiated high resistivity Si samples after annealing for $24 \mathrm{~h} @ 80^{\circ} \mathrm{C}$; (c) low resistivity $\mathrm{Si}$ samples. The full lines are fits to (6). 
be used for the interpretation of the Hall mobility dependences on temperature and fluence, therefore the magnetoresistance measurements have priority over them.

The magnetoresistance mobility dependence on temperature was similar to that predicted for the scattering on the macroinhomogeneities (clusters) [24], and the mobility dependence on temperature can be approximated by the proposed linear dependence on temperature (Fig. 3(a)). In the annealed samples the mobility value at room temperature was not far away from that limited by the scattering with phonons in the annealed samples irradiated to the $10^{12}$ $10^{13} \mathrm{~cm}^{-2}$ neutron fluence (Fig. $3(\mathrm{~b})$ ), therefore it was reasonable to analyse contributions of all possible scattering processes using the Matthiessen's rule and to use the approximation of the mobility dependence on temperature as $\mu=a_{i} T^{\alpha}$, where the $\alpha$ index depends on the scattering mechanism. This approximation was possible in a narrow range of the temperature, and the results are presented in Fig. 2(b) and the Table.

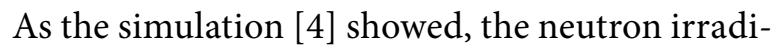
ation created a rather compact generation of defects, and the remaining material volume is free from defects. Therefore the simulation of the mobility dependence on temperature took into account the scattering of the carriers as in a high quality silicon crystal that could be approximated by power law $\mu=a T^{\alpha}$ with $\alpha \cong-2.1$ near to the $R T$, and the experimental values of $\alpha$ were found in a range of 1.5-2.42 [25]. The latter difference could be a result of additional scattering on the ionized impurities in differently doped crystals. The power index for the scattering on the point defects that can be charged is $\alpha=1.5$. If the defects are neutral, their contribution can be independent of temperature with $\alpha=0$ [26]. The scattering on clusters is the most indefinite: it could follow the same dependences with $\alpha=-1.0$ or $-5 / 6$ [24], or show the contribution of dipole scattering that could appear due to the difference of va- cancies and interstitials distribution inside the cluster. The dipole scattering can be approximated by $\mu \sim T^{0.5}$ [27]. Therefore the fitting was performed by the relation

$$
\begin{aligned}
& \mu=1 /\left(1 / \mu_{\text {phon }}+1 / \mu_{\text {ionized }}+1 / \mu_{\text {clusters }}+1 / \mu_{\text {dipoles }}\right) \\
& =1 /\left[1 /\left(a T^{\alpha}\right)+1 /\left(b T^{1.5}\right)+1 /\left(c T^{-1}\right)+1 /\left(d T^{0.5}\right)\right]
\end{aligned}
$$

and here $\mu_{\text {phon }}$ means the mobility of electrons in the non-irradiated sample. It was not found during the fit because of the necessity to include scattering on the neutral impurities.

The weak dependence of the magnetoresistance mobility on temperature (Fig. 3(a)) necessitated the inclusion of the scattering processes with positive and negative $\alpha$, i. e. the scattering on the ionizing impurities or (and) the dipoles took place. The same, only stronger, dependence of the mobility on temperature was observed in the irradiated low resistivity samples (Fig. 3(c)) in which the defect space charge was screened better than in the high resistivity silicon. As significant changes of the electron mobility dependence appear in the samples irradiated to the higher fluence than $10^{14} \mathrm{~cm}^{-2}$, the fitting of the experimental results to any combination of different scattering centres contributed by the Matthiessen's rule was performed in the less irradiated samples. The fitting results can be used only on the qualitative level due to a necessity to include many parameters in the analysis and the scattering of the experimental data. Therefore it was possible to model the dependences as shown in the figures, and the main result was evaluation of the contributions of the dependences with low positive and negative $\alpha$ values to obtain a fit. A similar compliance with the data can be achieved with several combinations of the dependences with positive and negative $\alpha$ values, and only for the demonstration the fitting parameters are given in the Table, so it requires more precise experiments later.

Table. The parameters used for a fit of the experimental data to Eq. (6). The mobility values in (6) are given in units

\begin{tabular}{|c|c|c|c|c|c|c|c|}
\hline & \multirow{2}{*}{ Fluence, $\mathrm{cm}^{-2}$} & \multirow{2}{*}{ Sample } & \multicolumn{2}{|c|}{ Phonons } & \multirow{2}{*}{$\begin{array}{c}\text { Ionized point } \\
\text { defects } \alpha=1.5, b\end{array}$} & \multirow{2}{*}{$\begin{array}{c}\text { Clusters } \\
\alpha=-1.0, c\end{array}$} & \multirow{2}{*}{$\begin{array}{c}\text { Dipoles } \\
\alpha=-0.5, d\end{array}$} \\
\hline & & & $\alpha$ & $a$ & & & \\
\hline 1 & $1 \cdot 10^{12}$ & HR & -1.4 & $4.6 \cdot 10^{6}$ & 1 & $1 \cdot 10^{7}$ & $4 \cdot 10^{3}$ \\
\hline 2 & $1 \cdot 10^{13}$ & HR & -1.4 & $4.6 \cdot 10^{6}$ & 0.8 & $2 \cdot 10^{6}$ & $1.5 \cdot 10^{3}$ \\
\hline 3 & Nonirradiated & KEF2 & -2 & $1.1 \cdot 10^{8}$ & 4 & 0 & 0 \\
\hline 4 & $1 \cdot 10^{14}$ & KEF2 & -2 & $1.1 \cdot 10^{8}$ & 3.3 & $1.2 \cdot 10^{8}$ & $3.4 \cdot 10^{3}$ \\
\hline 5 & $1 \cdot 10^{15}$ & KEF2 & -2 & $1.15 \cdot 10^{8}$ & 8 & $4 \cdot 10^{7}$ & $5 \cdot 10^{3}$ \\
\hline
\end{tabular}
$\mathrm{cm}^{2} /(\mathrm{sV})$, and the temperature is given in $\mathrm{K}$. 


\subsection{Electron concentration dependence on the neutron irradiation fluence}

The measured values of mobility permitted the analysis of the temperature dependence of the free electron concentration which is presented in Fig. 4 .

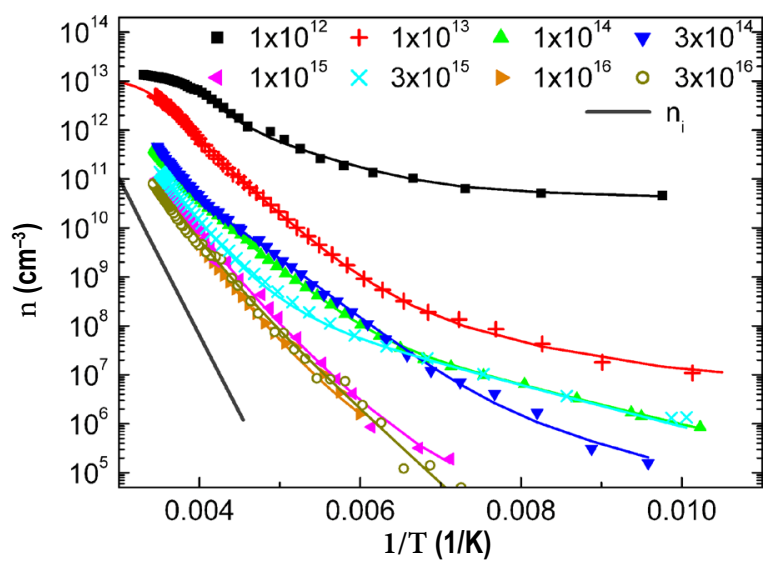

Fig. 4. The temperature dependence of the electron concentration in the irradiated samples. The fluence value in neutrons $/ \mathrm{cm}^{2}$ is given in the insets. The lines correspond to the results of fitting to the experimental data, and the parameters are given in Fig. 6. The experimental data errors are within the symbol size; an example is shown for the case of $10^{13} \mathrm{~cm}^{-2}$ in which the error bars are presented.

The analysis of different local level contribution was performed following the classical expressions [28], and it requires a model to choose [29] according to the position of the Fermi level which is relevant to the proposed level activation energy. The Fermi level dependence on temperature (Fig. 5) was used for this purpose $\left(F=E_{\mathrm{C}}-k T \ln \left(n / N_{\mathrm{C}}\right)\right)$. Therefore a partly compensated semiconductor approximation was used if the Fermi level was below the corresponding level. Then the carrier density is

$$
n=\left(N_{\mathrm{M}}-N_{K}\right) /\left[1+\left(\beta N_{K} / N_{\mathrm{C}}\right) \exp \left(\Delta E_{\mathrm{M}} / k T\right)\right] \text {, }
$$

where $N_{\mathrm{M}}$ is the deep level concentration, $N_{\mathrm{C}}$ is the density of states in the conduction band, $\beta$ is the deep level degeneration factor, $\Delta E_{\mathrm{M}}$ is the deep level activation energy, $k$ is the Boltzmann constant and $N_{K}$ is the concentration of the compensating deep levels. When the Fermi level was at or above the deep level energy, the noncompensated semiconductor case was used [29]:

$$
n=N_{\mathrm{M}} /\left[1+\sqrt{\left.1+\left(4 \beta N_{\mathrm{M}} / N_{\mathrm{C}}\right) \exp \left(\Delta E_{\mathrm{M}} / k T\right)\right]} .\right.
$$

The latter case was possible to be used only for the level at $E_{\mathrm{C}}-E_{\mathrm{M}}=0.22 \mathrm{eV}$ in the sample irradi-

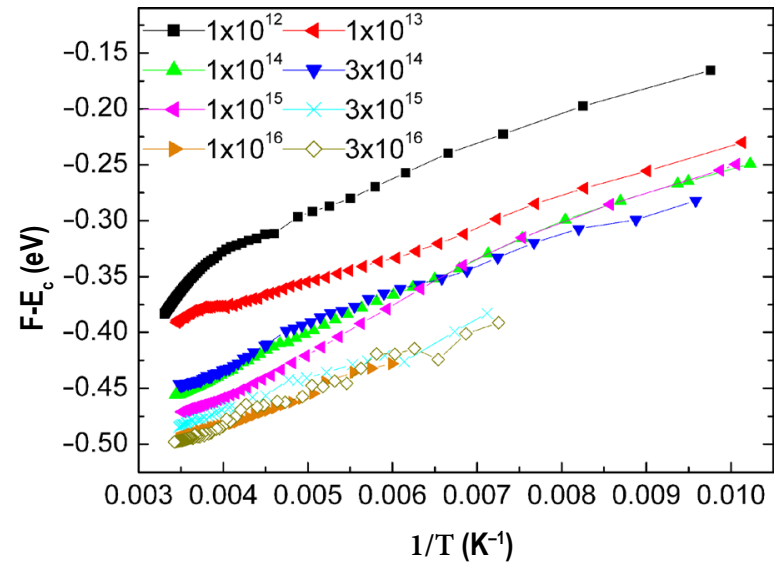

Fig. 5. The temperature dependence of the Fermi level in the irradiated samples. The fluence value in neutrons $/ \mathrm{cm}^{2}$ is given in the insets. The dash lines correspond to the levels used for the fits of the experimental data.

ated with the neutron fluence $10^{12} \mathrm{~cm}^{-3}$. In the case of a higher irradiation sample, the Fermi level was at the value of the activation energy, but if Eq. (8) would be used, the deep centre thermal activation energy would be more than $0.8 \mathrm{eV}$, and that is impossible in silicon. Therefore Eq. (7) is used, and the model of the cluster explaining a possibility to apply this relation is proposed, and it is given below. It is necessary to point out that in our samples the Fermi level did not reach the middle of the bandgap, therefore the intrinsic conductivity and the change of the conductivity type were not observed.

Employing the above approximations, the results of fitting are presented in Fig. 6, and the following details are pointed out: 1) in the sample irradiated to $10^{12} \mathrm{~cm}^{-2}$ fluence, a very weak free carrier concentration dependence on temperature (at low temperature) reveals the concentration of fully ionized shallow levels that are not compensated by deep levels of approximately $5 \cdot 10^{10} \mathrm{~cm}^{-3}$. At higher temperature the activation energy was comparable to the Fermi level distance from the conductivity band. The activation energy of $220 \mathrm{meV}$ was determined from Eq. (8), but for the fit to the experimental data it was necessary to add a contribution of a deeper level with the activation energy according to Eq. (7) equal to $360 \mathrm{meV}$.

The observed levels at 0.36 and $0.22-0.23 \mathrm{eV}$ are known in irradiated $\mathrm{Si}$, and are caused by tri- and bivacancies, respectively [30]. In some higher irradiation fluence samples, a contribution of an additional shallow level was found with an activation energy of $70 \mathrm{meV}$, and it can also be related to tri- and bi-vacancies [30]. Within the range of the experimental error, the temperature dependence of the free carrier concentration could be approximated also by other sets of levels, but we required the same set of the levels for 
(a)

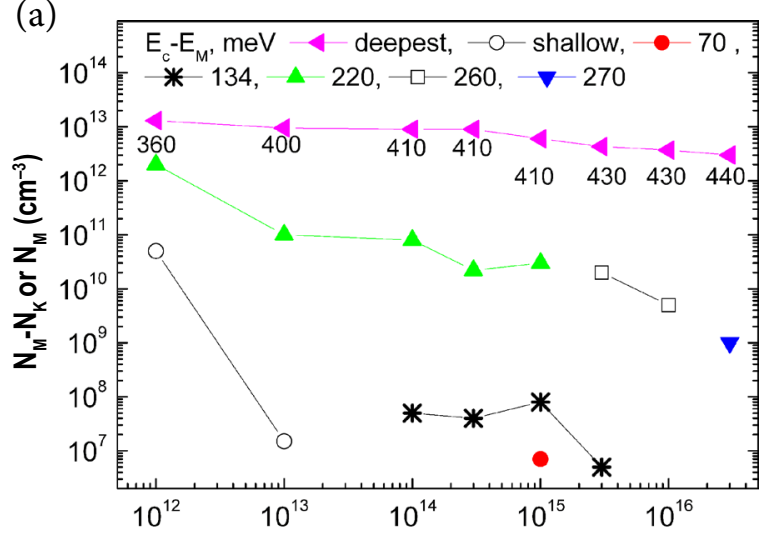

(b)

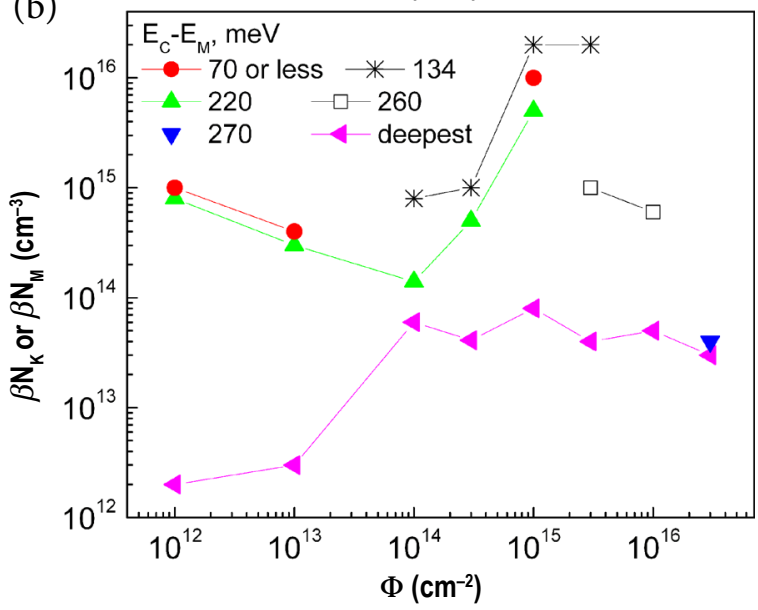

Fig. 6 . The concentration of local levels obtained by fitting the experimental data to Eqs. (7) and (8) in the samples irradiated to $10^{12}-3 \cdot 10^{16} \mathrm{~cm}^{-2}$ fluence. The local level energies are given in the insets and near the triangular dots (coloured online) if the energy of the level changes.

all samples irradiated to the fluences in the range $10^{12}$ $10^{14} \mathrm{~cm}^{-2}$. A more complicated situation was found in the case of the samples irradiated to the higher fluence. Here it was found that the free carrier concentration activation energy depended on the fluence, indicating the existence of an indirect interaction between the radiation defects. The absence of the direct interaction in this range of the fluence was demonstrated in [31] by the linear dependence of the generation current on the fluence in the irradiated diode structures.

The fitting parameters for all samples are given in Fig. 6 . The accuracy of the fitting parameters was better than $5 \%$, therefore the scattered values of the effective concentration of $N_{K}$ or $N_{\mathrm{M}}$ levels could be interpreted in terms of an inhomogeneous environment of the deep levels in the semiconductor. The same situation was observed in the higher doping samples.

The important feature is related to the impact of the fluence on the deep level concentration. The decrease of the deep level contribution to the conductivity, i. e. the concentration of the deep levels that are ob- tained by fitting of the experimental results to Eqs. (7) and (8) with the fluence, indicates a more effective simultaneous increase of the acceptor like deep levels in the lower part of the bandgap. The increased concentration of the deep levels in the lower part of the bandgap was previously shown in the neutron irradiated silicon by the measurement of photoconductivity in the extrinsic region [32].

The necessity to apply a partly compensated semiconductor model in the case of deep levels that are below or at the Fermi level can be explained by the cluster model presented in Fig. 目.

This experimental fact suggests that this type of a deep level is associated with defect clusters, and leads to the proposed modification of known cluster models [24, 33-34]. The proposed model includes the necessity of the contribution of multiphonon-assisted tunneling from the levels in the cluster to the states in the conduction band (a dot arrow in Fig. 7), similar to the model analysed in [34]. The tunneling efficiency depends on the tunnelling barrier thickness that is related to the Debye radius around the cluster. The irradiation reduced the bulk conductivity therefore the Debye length increased, and then the carriers in the deep level had to achieve higher thermal energy to participate in the tunnelling to the conduction band. It explains the result that activation energy of the deepest level is greater in the samples irradiated to the higher fluence (Fig. 6).

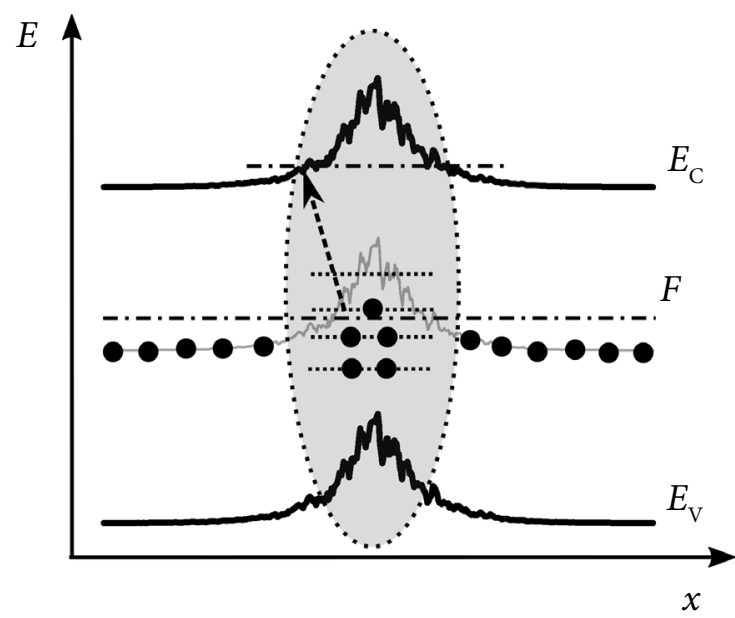

Fig. 7. A model of the cluster. The dotted ellipse shows the central part of the cluster, composed of a random distribution of defects [3], which introduce structural changes inside the cluster and form a series of levels that are shown as full black dots. $F$ is the Fermi level. The small grey dots present the deep levels in the bulk of the crystal. The arrows show the initial and the final states that participate in the multiphonon assisted tunneling from the cluster levels to the conduction band states. 


\section{Conclusions}

The electron mobility dependence on the neutron irradiation with fluencies of $10^{12}-3 \cdot 10^{16} \mathrm{~cm}^{-2}$ was observed in the dark conductivity in silicon.

The annealing of the irradiated silicon for $24 \mathrm{~h}$ at $80{ }^{\circ} \mathrm{C}$ restored the mobility to the initial values if the samples were irradiated to the fluence $10^{12}-10^{13} \mathrm{~cm}^{-2}$, but in the higher fluence samples the electron mobility remained less than in the initial crystals. It was proposed that the decrease of the mobility in the just irradiated silicon and in the silicon irradiated to the fluence of $10^{14}-10^{16} \mathrm{~cm}^{-2}$ and annealed for $24 \mathrm{~h}$ at $80^{\circ} \mathrm{C}$ was caused by the additional scattering centers and by the percolation character of the conductivity (at least at low bias).

The main contribution to the conductivity at the temperature near to room temperature was from the carriers thermally excited from the local levels inside the cluster leading to the dependence of the thermal activation energy on the irradiation fluence.

Neutron irradiation created deep levels in the upper half of the bandgap, as well as increased the concentration of the acceptor like levels that caused the decrease of the effective concentration of the deep levels responsible for the dark conductivity.

A modified cluster model was proposed.

\section{Acknowledgements}

This work was performed in the framework of the CERN RD50 collaboration. The work was partly funded by the Lithuanian Research Council, grant MIP-068, and the Lithuanian Academy of Sciences, grants CERN-VU-2013-2015.

\section{References}

[1] K. Wehe, Current trends in ionizing radiation detectors, Nucl. Eng. Technol. 38, 311-318 (2006), http://www.kns.org/jknsfile/v38/JK0383111.pdf

[2] M. Moll, J. Adey, A. Al-Ajili, G. Alfieri, P.P. Allport, M. Artuso, S. Assouak, B.S. Avset, L. Barabash, A. Barcz, et al., Development of radiation tolerant semiconductor detectors for Super-LHC, Nucl. Instrum. Methods A 546, 99-107 (2005), http:// dx.doi.org/10.1016/j.nima.2005.03.044

[3] M. Moll, E. Fretwurst, and G. Lindström, Investigation on the improved radiation hardness of silicon detectors with high oxygen concentration, Nucl. Instrum. Methods A 439, 282-292 (2000), http://dx.doi.org/10.1016/S0168-9002(99)00842-6

[4] M. Huhtinen, Simulation of non-ionising energy loss and defect formation in silicon, Nucl. Instrum. Methods A 491, 194-215 (2002), http://dx.doi. org/10.1016/S0168-9002(02)01227-5
[5] T.J. Brodbeck, A. Chilingarov, T. Sloan, E. Fretwurst, M. Kuhnke, and G. Lindstroem, Carrier mobilities in irradiated silicon, Nucl. Instrum. Methods A 477, 287-292 (2002), http://dx.doi.org/10.1016/S01689002(01)01858-7

[6] E. Borchi, M. Bruzzi, B. Dezillie, S. Lazanu, Z. Li, and S. Pirollo, Hall effect analysis in irradiated silicon samples with different resistivities, IEEE Trans. Nucl. Sci. 46, 834-838 (1999), http://dx.doi. org/10.1109/23.790687

[7] V. Eremin and Z. Li, Carrier drift mobility study in neutron irradiated high purity silicon, Nucl. Instrum. Methods A 362, 338 (1995), http://dx.doi. org/ 10.1016/0168-9002(95)00381-9

[8] R.H. Bube, Interpretation of Hall and photo-Hall effects in inhomogeneous materials, Appl. Phys. Lett. 13, 136-139 (1968), http://dx.doi.org/10.1063/ 1.1652542

[9] W. Siegel, S. Schulte, C. Reichel, G. Kuhnel, and J. Monecke, Anomalous temperature dependence of the Hall mobility in undoped bulk GaAs, J. Appl. Phys. 82, 3832-3835 (1997), http://dx.doi. org/10.1063/1.365747

[10] V.G. Karpov, A.J. Shik, and B.I. Shklovskii, Theory of the Hall effect in randomly inhomogeneous semiconductors, Sov. Phys. Semiconduct. 16, 901-903 (1982).

[11]J. Vaitkus, A. Mekys, G. Mockevičius, J. Storasta, and N. Vainorius, in: Materials of 4th International Conference on Radiation Interaction with Material and Its Use in Technologies 2012 (Technologija, Kaunas, 2012) pp. 33-38.

[12]D.K. Schröder, Semiconductor Material and Device Characterization (Wiley, N. Y., 1990).

[13]P. Norton, T. Braggins, and H. Levinstein, Impurity and lattice scattering parameters as determined from Hall and mobility analysis in $n$-type silicon, Phys. Rev. B 8, 5632-5653 (1973), http://dx.doi. org/10.1103/PhysRevB.8.5632

[14]A.C. Beer, Galvanomagnetic Effects in Semiconductors (Academic Press, N. Y., 1963).

[15]A. Mekys, V. Rumbauskas, J. Storasta, L. Makarenko, and J.V. Vaitkus, Defect analysis in fast electron irradiated silicon by Hall and magnetoresistivity means, Nucl. Instrum. Methods B 338, 95-100 (2014), http://dx.doi.org/10.1016/j. nimb.2014.08.007

[16] A. Mekys, V. Rumbauskas, J. Storasta, L. Makarenko, N. Kazuchits, and J.V. Vaitkus, Hall effect and magnetoresistance investigation of fast electron irradiated silicon, Lith. J. Phys. 54, 94-98 (2014), http:// dx.doi.org/10.3952/lithjphys.54204

[17]C. Jacoboni and P. Lugli, The Monte Carlo Method for Semiconductor Device Simulation (Springer Science \& Business Media, 2012).

[18] K.W. Böer, Handbook of the Physics of Thin-Film Solar Cells (Springer Science \& Business Media, Berlin, 2014). 
[19]B.K. Ridley, Reconciliation of the Conwell-Weisskopf and Brooks-Herring formulae for chargedimpurity scattering in semiconductors: Third-body interference, J. Phys. C 10 (1977), http://dx.doi. org/10.1088/0022-3719/10/10/003

[20] E. Verbitskaya, V. Eremin, Z. Li, J. Harkonen, and M. Bruzzi, Concept of Double Peak electric field distribution in the development of radiation hard silicon detectors, Nucl. Instrum. Methods A 583, 77-86 (2007), http://dx.doi.org/10.1016/j. nima.2007.08.228

[21] H.J. Stein., Electrical studies of neutron-irradiated n-type Si: defect structure and annealing, Phys. Rev. 163(3), 801-808 (1967), http://dx.doi.org/10.1103/ PhysRev.163.801

[22]H.J. Juretschke, R. Landauer, and J.A. Swanson, Hall effect and conductivity in porous media, J. Appl. Phys. 27, 838 (1956), http://dx.doi. org/10.1063/1.1722496

[23] W. Siegel, S. Schulte, G. Kühnel, and J. Monecke, Hall mobility lowering in undoped $n$-type bulk GaAs due to cellular-structure related nonuniformities, J. Appl. Phys. 81, 3155-9 (1997), http://dx.doi. org/10.1063/1.364350

[24] L.R. Weisberg, Anomalous mobility effects in some semiconductors and insulators, J. Appl. Phys. 5, 18171821 (1962), http://dx.doi.org/10.1063/1.1728839

[25] C. Jacoboni, C. Canali, G. Ottaviani, and A. Alberigi Quaranta, A review of some charge transport properties of silicon, Solid State Electron. 20(2), 77-89 (1977), http://dx.doi.org/10.1016/0038-1101(77)90054-5

[26] K. Seeger, Semiconductor Physics (Springer-Verlag, Wien, New York, 1973).

[27]W. Zhao and D. Jena, Dipole scattering in highly polar semiconductor alloys, J. Appl. Phys. 96, 20952101 (2004), http://dx.doi.org/10.1063/1.1767615
[28]M. Sze, Physics of Semiconductor Devices (Wiley, New York, 1981).

[29]J.S. Blakemore, Semiconductor Statistics (Pergamon Press, Oxford, 1962).

[30]B.J.Svensson, M.J. Rayson, P.R. Briddon, J. Coutinho, V.P. Markevich, A.R. Peaker, B. Hamilton, S.B. Lastovskii, and L.I. Murin, Electronic and dynamical properties of the silicon trivacancy, Phys. Rev. B 86, 174101 (2012), http://dx.doi.org/10.1103/ PhysRevB.86.174101

[31] G. Lindström, M. Moll, and E. Fretwurst, Radiation hardness of silicon detectors - a challenge from high-energy physics, Nucl. Instrum. Methods A 426, 1-15 (1999), http://dx.doi.org/10.1016/S01689002(98)01462-4

[32] V. Kalendra, E. Gaubas, V. Kazukauskas, E. Zasinas, and J. Vaitkus, Photoconductivity spectra and deep levels in the irradiated $\mathrm{p}^{+}-\mathrm{n}-\mathrm{n}^{+}$Si detectors, Nucl. Instrum. Methods A 612, 555-558 (2010), http:// dx.doi.org/10.1016/j.nima.2009.08.043

[33]P.F. Ermolov, D.E. Karmanov, A.K. Leflat, V.M. Manankov, M.M. Merkin, and E.K. Shabalina, Neutron irradiation-induced effects caused by divacancy clusters with a tetravacancy core in float-zone silicon, Semiconductors 36, 1114-1122 (2002), http://dx.doi.org/10.1134/1.1513854

[34] R.M. Fleming, C.H. Seager, D.V. Lang, P.J. Cooper, E. Bielejec, and J.M. Campbell, Effects of clustering on the properties of defects in neutron irradiated silicon, J. Appl. Phys. 102, 043711 (2007), http:// dx.doi.org/10.1063/1.2769783

[35] P.C. Serce, Multiphonon-assisted tunneling through deep levels: A rapid energy-relaxation mechanism in nonideal quantum-dot heterostructures, Phys. Rev. B 51, 14532-14541 (1995), http://dx.doi. org/10.1103/PhysRevB.51.14532

\title{
APŠVITOS NEUTRONAIS İTAKA ELEKTRONŲ JUDRIUI IR TAMSINIO LAIDUMO KOMPENSACIJAI SILICIO KRISTALUOSE
}

\author{
J.V. Vaitkus, A. Mekys, V. Rumbauskas, J. Storasta \\ Vilniaus universiteto Taikomujų mokslu institutas ir Fizikos fakulteto Puslaidininkiu fizikos katedra, Vilnius, Lietuva
}

\begin{abstract}
Santrauka
Tirti elektronų pernašos reiškiniai silicio kristaluose, apšvitintuose reaktoriaus neutronais, panaudojant Holo efekto ir magnetovaržos metodikas. Analizuotos elektronų judrio ir krūvininkų koncentracijos prieklausos nuo neutronų ịtèkio ir temperatūros. Parodyta, kad elektronų judris mažèja didinant neutronų ịtėkị plačiame itèkių intervale, ir bandiniuose sukuriami mikronevienalytiškumai, lemiantys elektronų judrio, nustatomo iš Holo efekto ir magnetovaržos, skirtumus. Panaudojant magnetovaržinio judrio vertes nustatyta elektronų koncentracijos prieklausa nuo temperatūros, o ją anali-
\end{abstract}

zuojant gautos lokalinių lygmenų aktyvacijos energijos ir jų koncentracijos. Gauta, kad apšvita neutronais sukuria lygmenis viršutinèje draustinès juostos pusèje, tačiau jų įtaka tamsiniam kristalų elektriniam laidumui didèjant neutronų ittèkiui mažeja, nes sukuriama didesnè akceptorių koncentracija draustinès juostos viduryje ar jos apatinejje dalyje. Nustatyta, kad laisvųjų krūvininkų koncentracijos aktyvacijos energija netenkina vienalyčio puslaidininkio modelio, todèl sukurtas modifikuotas defektu klasterio modelis ir paaiškinta puslaidininkio tamsinio laidumo prigimtis, nusakanti klasterio ir jo apsupties savybes. 